\title{
Língua e cultura em contexto multilingue: um olhar sobre o sistema educativo em Moçambique
}

\section{Language and culture in a multilingual context: An overview at the education system in Mozambique}

\section{Langue et culture dans un contexte multilingue: un regard sur le système éducatif au Mozambique}

\author{
Amélia Francisco Filipe da C. Lemos*
}

\begin{abstract}
RESUMO
No presente texto pretendo fazer uma revisão bibliográfica à volta das principais questões ligadas à educação e ao ensino-aprendizagem em Moçambique no que concerne o ensino primário e secundário geral. Interessa-me sobretudo analisar três questões que julgo cruciais para a educação escolar em Moçambique, a saber: a) A definição da política linguística, b) as línguas e o sistema educativo e, c) $\mathrm{O}$ ensino-aprendizagem num contexto multilingue e plurilingue. Essas três questões que são amplamente abordadas por estudiosos e universitários na área da linguística e da sociolinguística devem, a meu ver, contribuir para uma reflexão à volta do que é preciso mudar ou melhorar no sistema educativo em Moçambique, para que o sucesso escolar não seja uma utopia. Servir-me-ei de conceitos como, multilinguismo, plurilinguismo, pluricultura e intercultura, cruzando deste modo as áreas da linguística, da sociolinguística e da antropologia cultural, para tentar verificar sob que prisma os textos que escolhi para minha análise (Menezes, 2013; Timbane, 2014; Henriksen, 2017; Noa, 2017) abordam a questão da educação em Moçambique.

Palavras-chave: Política linguística. Multilinguismo. Plurilinguismo. Intercultura e Educação.

*Universidade Pedagógica. Maputo, Moçambique. E-mail: ameli350@hotmail.com. ORCID: https://orcid.org/0000-0001-6992-3565
\end{abstract}




\begin{abstract}
In the present text I intend to make a bibliographical review of the main issues related to education and to the teaching and learning process in Mozambique, in what respects general primary and secondary education. I am particularly interested in analyzing three issues, which I believe are crucial for formal schooling in Mozambique, namely: (a) The definition of a language policy; (b) Languages and the education system; and (c) Teaching and learning in a multilingual and pluricultural context. These three issues, which are widely discussed by scholars and the academia in the field of linguistics and sociolinguistics, must, in my opinion, contribute to a reflection on what needs to be changed or improved in the education system in Mozambique, so that school success is not utopia. I will use concepts such as multilingualism, plurilingualism, pluriculture and interculture, thus crossing the areas of linguistics, sociolinguistics and cultural anthropology, in order to try to ascertain from what perspective the texts I have chosen for my analysis (Menezes, 2013; Timbane, 2014; Henriksen, 2017; Noa, 2017) address the issue of education in Mozambique.
\end{abstract}

Keywords: Language Policy. Multilingualism. Plurilingualism. Interculture and Education.

\title{
RÉSUMÉ
}

Dans le présent texte, j'ai l'intention de faire une revue bibliographique sur les principales questions liées à l'éducation et à l'enseignement/apprentissage au Mozambique concernant l'enseignement primaire et secondaire général. Je suis particulièrement intéressée par l'analyse de trois questions qui me semblent cruciales pour l'éducation scolaire au Mozambique: (a) la définition de la politique linguistique, (b) les langues et le système éducatif et (c) l'enseignement/apprentissage dans un contexte multilingue et pluriculturel. Ces trois questions, largement débattues par des chercheurs et des universitaires dans le domaine de la linguistique et de la sociolinguistique, devraient, à mon avis, contribuer à une réflexion sur ce qui doit être changé ou amélioré dans le système éducatif mozambicain pour que le succès scolaire ne soit pas une utopie. Je ferai appel à des concepts que le multilinguisme, le plurilinguisme, la multi-culturalité et interculturel, traversant ainsi les domaines de la linguistique, la sociolinguistique et de l'anthropologie culturelle, Pour essayer de vérifier sur quelle perspective les textes que j'ai arrêtés pour mon analyse (Menezes, 2013; Timbane, 2014; Henriksen, 2017; Noa, 2017) analysent la question de l'éducation au Mozambique.

Mots-clés: Politique Linguistique. Multilinguisme. Plurilinguisme. Interculture et Éducation. 


\section{Introdução}

Em vários textos nos quais abordei a questão da língua e do contexto multilingue em Moçambique, Lemos (2011, p. 120); (2014, p. 49); (2014, p. 13), por exemplo, preocupei-me com a língua ou com as línguas em presença no sistema educativo e a forma como estas são encaradas na escola. Se partirmos do princípio de que a língua é o veículo pelo qual o ensino é transmitido, o meio a partir do qual a comunicação em direção a vários níveis é estabelecida na escola e na sala de aula, por um lado, e se considerarmos, por outro lado, que o contexto moçambicano coloca-nos diante de um cenário onde várias línguas e culturas coabitam no espaço escola, e que essas línguas e culturas transportam com elas modos de vida, de ser, de estar e de pensar, devemos nos interrogar: que língua será mais apropriada para veicular conhecimentos e interagir com os alunos na escola? Que língua seria mais apropriada para privilegiar a expressão das várias línguas e culturas que o sistema educativo em vigor teima em fazer calar?

O sistema educativo em Moçambique apresenta dificuldades de várias ordens. De maneira rápida, mencionarei aqui três sobejamente conhecidas pelos encarregados de educação, os professores e os concetores de programas escolares. A primeira dificuldade prende-se com a leitura e a escrita, pois são muitas as crianças que estando na terceira ou quarta classe (ensino básico) não sabem ler nem escrever. A segunda está ligada ao absenteísmo. Muitas crianças abandonam a escola nos primeiros anos de escolaridade, por várias razões: casamentos prematuros, no caso da rapariga, dificuldades financeiras, distâncias longas entre o local de residência e a escola, etc. A terceira reside na maneira como a escola está organizada em termos de infrastruturas. Ainda existem muitas escolas cujas salas estão completamente desprovidas de mobiliário e de material didáctico, são muitas as escolas em que os alunos têm aulas por baixo das árvores, principalmente nas zonas rurais e periurbanas. Na época chuvosa e no inverno, quase não há aulas. Esses três cenários associados geram uma série de outros problemas que acumulados acabam contribuindo para o insucesso escolar. Dessas três dificuldades, interessa-me analisar a primeira pelo facto de estar ligada à língua, sobretudo à língua portuguesa e a sua relação com as outras línguas (bantus e estrangeiras).

No presente texto, pretendo fazer uma revisão bibliográfica à volta das principais questões ligadas à educação e ao ensino-aprendizagem em Moçambique no que concerne ao ensino primário e secundário geral. Interessa-me sobretudo analisar três questões que julgo cruciais para a educação escolar em Moçambique, a saber: 
a) a definição da política linguística;

b) as línguas e o sistema educativo;

c) o ensino-aprendizagem num contexto multilingue e plurilingue.

Essas três questões que são amplamente abordadas por estudiosos e universitários na área da linguística e da sociolinguística devem, a meu ver, contribuir para uma reflexão à volta do que é preciso mudar ou melhorar no sistema educativo em Moçambique, para que o sucesso escolar não seja uma utopia. Servir-me-ei de conceitos como, multilinguismo, plurilinguismo, pluricultura e intercultura, cruzando deste modo as áreas da linguística, da sociolinguística e da antropologia cultural, para tentar verificar sob que prisma os textos que escolhi para minha análise (Menezes, 2013; Timbane, 2014; Henriksen, 2017; Noa, 2017) abordam a questão da língua, cultura-intercultura e educação em Moçambique.

\section{Alguns conceitos}

As preocupações à volta da educação são comuns em todo o mundo. Educar um povo implica em garantir o desenvolvimento da nação. Educação, que significa acto de educar, de instruir, de disciplinar e mesmo de formar, pode ser compreendida de várias formas. Etimologicamente, educação vem do latim "EDUCARE, derivada de ex (fora ou exterior) e DUCERE (guiar, instruir, conduzir), o que pressupõe levar para si mesmo ou para o mundo. A educação foi sempre objecto de estudo por parte dos filósofos, que consideram que as sociedades não podem se sustentar sem educação. Para Sócrates, por exemplo, que se dedicava a ensinar na praça pública, a sua actividade era um convite ao saber. Num sentido mais amplo, educação reflete o modo como são passados de geração em geração, a cultura, os hábitos e costumes, as tradições e valores de uma certa comunidade ou sociedade. Quando falamos em boa ou má educação, referimo-nos a esses valores. Num sentido mais restrito, temos a educação que é o resultado de um processo sucessivo de formação intelectual, moral e física do indivíduo para que possa se integrar melhor no seio da sua comunidade e contribuir para o desenvolvimento da sociedade onde está inserido. Podemos assim nos referir a vários tipos de educação: formal-informal, artística, financeira, escolar, etc. Em Moçambique, "há dois tipos de educação: a tradicional e a formal. A educação tradicional corresponde aos ritos de iniciação que têm por objetivo transmitir normas e valores do grupo étnico, preparando a criança para a vida adulta. Essa educação entra em contradição com a educação formal nos 
dias de hoje" (Timbane, 2014, p. 2). Este autor assinala, citando o Ministério e Educação que "muitas práticas socioeconómicas e a divisão social do trabalho na comunidade, que constituem aprendizagens no âmbito da educação familiar, são fatores que, muitas vezes, condicionam a participação das crianças nas atividades escolares e põem em causa o próprio valor da escola." (Ministério da Educação, 2003, p. 12). Este é mais um factor que contribui negativamente para o sucesso escolar.

A educação escolar, por exemplo, é a que se preocupa com a formação formal do indivíduo valendo-se de um sistema de ensino, em função de políticas definidas pelos dirigentes de um determinado país. Neste caso, a língua torna-se um factor importante porque é por meio dela que se estabelecem as relações, primeiro a um nível pessoal, familiar e posteriormente, numa relação com a comunidade e a sociedade. Partindo do conceito de língua de Saussure (Cours de Linguistique Générale), na sua dimensão homogénea e estruturante, a linguística considera actualmente que a língua deve ser encarada numa dimensão heterogénea, pois ela é o resultado das práticas sociais e não um sistema, isolado da actividade humana. É esta actividade humana que coloca a língua numa constante interação com outras línguas, com o desenvolvimento das sociedades e com as suas necessidades. Num contexto de línguas em contacto e coexistindo num mesmo espaço, as línguas interagem entre si e acabam exercendo influências umas sobre as outras, independentemente da vontade ou não das pessoas. Nesse sentido, estabelece-se a relação língua e sociedade visto que a língua só pode existir como um sistema dinâmico, colocando os indivíduos numa interação entre a estrutura linguística e a estrutura social. No meu contexto de intervenção, existe uma coexistência não muito pacífica entre as línguas moçambicanas de origem bantu, a língua portuguesa, que é a língua oficial (de escolaridade) e as línguas estrangeiras, o inglês e o francês. Para além dessas línguas, existem igualmente as línguas asiáticas e islâmicas. Estas circulam em comunidades mais fechadas, sendo as islâmicas mais presentes no norte do país. É o caso do hindu, urdo, gujarate, memane e o árabe. Estamos assim diante de um contexto multilingue e pluricultural.

O multilinguismo, que é segundo o Quadro Europeu Comum de Referência para as línguas, um contexto onde várias línguas coabitam ou coexistem - “ Uma sociedade multilingue pode ser maioritariamente formada de indivídios monolingues que ignoram a língua do outro", enquanto que uma sociedade plurilingue é "composta maioritariamente de indivíduos capazes de se exprimir a diversos níveis de competência em várias línguas", (CECRL, 2000, p. 11). No caso da escola moçambicana, por exemplo, no meio urbano, coexistem várias línguas, entre elas, o português, o inglês e o francês, línguas adoptadas para o sistema educativo e as línguas bantu (LB), que são línguas maternas de 
vários alunos, mas que não encontram força de expressão, pelo menos no meio formal. Por outro lado, falar de multilinguismo significa igualmente falar de multiculturalismo, pois a língua veicula a cultura e com ela, o modo de estar, de pensar, de agir, de raciocinar, etc. O conceito de multilinguismo não pode ser visto como sendo só o caso de coexistência de línguas. Para Calvet $(2001)^{1}$, não existem países monolingues. Podem existir várias formas de uma mesma língua. Ele explica que o plurilinguismo é a forma mais corrente e que há duas formas de o conceber: « seja como fenómeno individual (um indivíduo plurilingue, que manipula várias línguas, vive entre várias línguas, porque nasceu no seio de um casal bilingue, ou porque viajou ou estudou muito) seja como fenómeno colectivo (uma comunidade plurilingue, na qual coexistem várias línguas)". No caso de Moçambique, podemos observar na escola, classes onde coexistem várias línguas, em que, na maioria dos casos, os alunos são bilingues, alguns plurilingues (falando mais de duas línguas) e outros ainda monolingues. No entanto, para Coste et al., "O plurilinguismo não descreve competências fixas. Os indivíduos desenvolvem competências em vários códicos linguísticos, por vontade ou por necessidade, para responder às necessidades de comunicar com o outro que não partilha os mesmos códicos" (Coste et al, 2009, 16).

No espaço escola, num contexto de contacto de línguas, depara-se igualmente com um contacto de culturas. As políticas linguísticas determinam muitas vezes o modo como as línguas e as culturas devem ser conduzidas no sistema educativo e o modo como estas devem reflectir na vida do aluno e da sociedade. Segundo Cavalli et al (2009), o ideal, numa sociedade multilingue, é que a escola promova uma educação plurilingue e pluricultural, tendo em conta o contexto sociolinguístico e sociocultural, não ignorando o papel das representações sociais que pode ir contra a inovação. Estes autores defendem ainda que :

a educação plurilingue e intercultural não é também pensada para uma elite privilegiada, a que sempre se distinguiu por una certa forma de domínio de línguas estrangeiras, por exemplo. Ela é fundamentalmente inclusiva e ela pode ser implementada em todos os sectores educativos [...] Enfim, do ponto de vista didáctico e metodológico, a educação plurilingue e intercultural não deve ser considerada como uma nova metodologia para o ensino de línguas: ela representa antes de mais uma mudança de perspectiva, caracterizada pelo facto de que ela não integra somente as línguas estrangeiras mas as línguas circonvizinhas, as línguas do repertório dos alunos, as línguas de escolarização e todas as outras matérias. (Cavalli, 2009, p. 7).

1 1ère Table ronde 1ère table ronde, Identité et multiculturalisme, Identité et plurilinguisme. 
Quanto ao bilinguismo, nota-se que em Moçambique, a maioria dos falantes nas zonas urbanas, incluindo no contexto escolar, é bilingue na medida em que estes falante têm uma língua materna e uma língua segunda que lhes permite comunicar em função do contexto e das necessidades. A este propósito, Menezes aborda a questão da passagem de uma língua para a outra (code switching, Gumperz, 1982, p. 75), "fenômeno linguístico natural que consiste no uso alternado de dois ou mais códigos nas interações conversacionais entre indivíduos bilingues", (Menezes, 2013, p. 5). Ela explica que para o caso de Moçambique "Relativamente aos empréstimos linguísticos, sabe-se que estes ocorrem quando uma língua integra uma palavra existente em outra língua, sendo que a palavra não sofre grandes alterações e mantém o mesmo sentido. Algumas dessas palavras emprestadas de outras línguas no português passam por um processo de aportuguesamento que não deixa claro para o emissor que se trata de uma verdadeira influência que outras línguas exercem sobre a mesma", (Menezes, 2013, p. 6). Eu creio que o bilinguismo de que fala Menezes, "e o de fanates que não dominando a língua portuguesa e tendo necessidade de se comunicar com quem não fala a sua língua materna, integra na sua fala palavras e expressões emprestadas ou reenventadas/ reformuladas. Creio que se trata, para alguns casos, de uma apropriação linguística muitas vezes observada nos meios informais, como praças públicas, mercados informais, etc. Darei o exemplo de um recolhedor de ferro velho que circula por toda a cidade de Maputo, à procura desse tipo de material. Quando ele se encontra na zona urbana, utiliza uma gravação em português "Compro baterias, chaparia usado" e quando se encontra na zona periurbana utiliza uma outra gravação na sua língua materna. Essa situação difere do conceito de Cavalcanti (2007) que considera que um bom bilingue tem competência nas duas línguas.

\section{Que política linguística num contexto multilingue?}

A educação em Moçambique é marcada por dois momentos. O primeiro, na época colonial, em que a grande maioria dos Moçambicanos não tinha acesso à escola, esta era reservada aos filhos dos colonos e a uma minoria negra, chamada assimilada. A segunda após a independência, em 1975, em que o acesso à escola passou a ser para todos, inclusive com programas de alfabetização de adultos. Visto que Moçambique não dispunha de infrastruturas sufucientes, o acesso à educação para todos tornou-se um grande desafio para os dirigentes do Moçambique independente. Para Samora Machel, primeiro presidente de Moçambique, era necessário "fazer da escola uma base para o povo tomar o poder". 
Era preciso educar para a cidadania, para a formação de um homem novo, capaz de tomar as rédeas de uma nação recém-criada. A ideia de homem novo estava associada aos ideais do poder na altura. Um homem capaz de construir uma nação livre, inclusiva, combatento o analfabetismo e o regionalismo ${ }^{2}$. Muitos quadros portugueses abandonaram o país após a independência. Moçambique ficou desprovida de médicos, enfermeiros, professores, advogados, engenheiros, enfim, o país ressentiu-se de falta de quadros a todos os níveis. Portanto, era preciso pensar em construir um Moçambique pelos próprios moçambicanos. O sistema educativo conheceu assim uma grande reviravolta, o ensino pré-universitário e superior foram suspensos por alguns anos para garantir uma educação de base para todas as crianças. É nesse âmbito que surge a primeira política nacional de educação, em que a língua portuguesa, como nos referimos acima, é adotada como língua de escolaridade e a língua por meio da qual todos os moçambicanos deviam se comunicar, para salvaguardar a questão do regionalismo e tribalismo, assunto este ao qual também já nos referimos.

A política linguística de um país determina a escolha e o posicionamento dos responsáveis da educação em relação às línguas a serem ensinadas ou abordadas na escola. É a partir dessas escolhas que todo o sistema educativo e toda a cadeia que constitue o sistema (Ministério, direcções provinciais e distritais de educação, escolas, pais e encarregados de educação) se planifica, coordena as várias acções e vislumbra o futuro, em termos de formação de quadros. Como muitos países africanos, Moçambique, sendo um país multilingue e pluricultural, precisa de definir que línguas devem ser ensinadas ou privilegiadas na escola, tendo como visão o tipo de quadros que pretende formar e a cooperação com outros países com quem tem relações. Foi nessa perspetiva que as reformas no sector da educação foram efetuadas.

Ao nível dos documentos orientadores (PCEB e PCESG ${ }^{3}$ ) do Ministério da Educação e Desenvolvimento Humano ${ }^{4}$, as políticas linguísticas foram redefinidas e favorizam uma política de inclusão em relação às línguas e culturas nacionais e estrangeiras. Segundo o PCESG, o sistema educativo deve "Reconhecer a importância das línguas moçambicanas como contributo para o desenvolvimento da sua comunidade [...] Reconhecer a diversidade cultural do país incluindo a linguística, religiosa e política, aceitando e respeitando os membros dos grupos distintos do seu, desenvolvimento acções concretas que visam o respeito e preservação do património cultural", (PCESG, pp. 20 e 21).

$2 \mathrm{Na}$ altura colonial, a estratégia dos colonos era dividir para reinar. E o regionalismo e o tribalismo eram muito fomentados, o que era fonte de conflito e preconceito.

3 Plano Curricular do Ensino Básico e Plano Curricular do Ensino Secundário Geral.

4 Designação atual do Ministério. 
No entanto, sendo a língua portuguesa (LP) a língua nacional e língua de comunicação, o português detém a primazia diante das cerca de vinte e cinco línguas nacionais de origem bantu, que constituem as línguas maternas da maioria das crianças e jovens na escola, mesmo nos meios urbanos. De acordo com o Recenseamento Geral da População (2007), 85,2\% de moçambicanos falam as várias línguas bantus como língua materna contra $10,5 \%$ que falam português. Um outro dado fornecido pelo Instituto Nacional de Estatística indica que dos 25.727.911 milhões de moçambicanos, 17.546.436 milhões correspondem à população rural e 8.181.475, à população urbana (www.ine.gov.mz/ (07/04/2015). Lemos (2015, p. 332) explica que "Nas zonas rurais, o português é língua segunda e ainda assim para uma pequena minoria. Em certas zonas rurais, o português é língua estrangeira, principalmente nas regiões fronteiriças com o Malawi, o Zimbabwé, a Tanzania, a África do Sul e a Suazilândia”. Ainda segundo um estudo efectuado por Ngunga, linguista moçambicana (2014), 87\% de moçambicanos não falam português em casa.

Esta é mais uma língua de mobilidade social, de prestígio e urbana. Um outro linguísta moçambicano, Mabasso (2014) afirma que a língua portuguesa não é nacional e nunca a foi em Moçambique. Para ele, o conceito de língua nacional está ligado a uma série de fatores como valores de nacionalidade, autenticidade e aceitabilidade. Essa ideia justifica por que os documentos administrativos se apresentam só em português. Entretanto, a comunicação entre os dirigentes políticos e a maioria da população, na prática, é feita por meio de uma língua materna com recurso à interpretação, o que demonstra que os dirigentes estão conscientes de que não é possível comunicar-se com a população em português, principalmente a população das zonas rurais. Infelizmente, nesse processo de tradução/interpretação, muita informação se perde ou é deturpada, porque o tradutor não domina a língua portuguesa. Apesar de a política linguística atual prever a introdução das LB, ainda se assiste a uma imposição do português como língua a ser valorizada na escola.

"A maioria das crianças moçambicanas chega à escola (aos 6 anos) com pelo menos uma LB. Essa LB é proibida no recinto escolar, na sala de aulas e na comunicação no recinto escolar. Até as línguas estrangeiras (inglês e francês) têm espaço livre na escola, exceto as LB, que são as línguas maternas da maioria das crianças. Classificamos os alunos moçambicanos em dois tipos segundo a língua materna que trazem do seu meio familiar: (a) aqueles que têm a LP como língua materna e (b) aqueles que têm a LP como língua segunda" [...] (Timbane, 2014, p. 7). 
É preciso referir ainda que as LB foram integradas aos currículos como disciplinas opcionais, conforme ilustra o Plano curricular do $1^{\circ}$ Ciclo, abaixo (Quadro 1):

\section{QUADRO 1 - PLANO CURRICULAR DO $1^{\circ}$ CICLO DO ENSINO SEGUNDÁRIO} GERAL

\begin{tabular}{|l|l|l|}
\hline \multicolumn{1}{|c|}{ Áreas } & \multicolumn{2}{|c|}{ Disciplinas } \\
\hline $\begin{array}{l}\text { Comunicação e } \\
\text { Ciências Sociais }\end{array}$ & $\begin{array}{l}\text { Português } \\
\text { Inglês } \\
\text { História } \\
\text { Geografia }\end{array}$ & $\begin{array}{l}\text { Escolhe 1 (uma) no ciclo: } \\
\text { Línguas Moçambicanas } \\
\text { Artes Cénicas } \\
\text { Francês }\end{array}$ \\
\hline $\begin{array}{l}\text { Matemática e } \\
\text { Ciências Naturais }\end{array}$ & Matemática & \\
& Física & \\
& Biologia & \\
Química & \\
\hline Atividades práticas & Ed. Visual & \\
e Tecnológicas & Ed. Física & \\
& TIC' (na 10 Classe) & \\
& Disciplinas Profissionalizantes \\
Noções de empreendedorismo & \\
Agro-Pecuária, etc. & \\
\hline
\end{tabular}

FONTE: PCESG, 2007, p. 65.

Isso pressupõe que nem todos os alunos têm acesso as $\mathrm{LB}$, o que reforça a ideia de que a LP beneficia de um tratamento diferenciado e que de um certo modo existe uma contradição no próprio documento orientador quando se afirma que com as línguas moçambicanas se pretende "promover nos alunos a consciência do valor das línguas e cultura moçambicanas no contexto multilingue e multicultural, contribuindo para a sua melhor inserção na sociedade" (PCESG, p. 38). Se a disciplina é opcional, de que modo este objectivo envolve e beneficia todos os alunos? O que se espera de um ensino-aprendizagem em contexto multilingue e pluricultural?

Falando sobre a importância das línguas e culturas no sistema educativo, Monjane Henriksen (2007) faz uma vasta explanação sobre o reportório linguístico ao nível da África e de Moçambique, colocando em realce a importância desse mosaico linguístico e cultural como "um recurso provável de beneficiar não só cada um dos moçambicanos, mas também o país como um todo" (Henriksen, 2007, 54). Que as línguas presentes num contexto multilingue constituem mais uma vantagem que um empecilho, estou plenamente de acordo. A questão que coloco é: Como fazer com que esse mosaico seja bem capitalizado na escola 
para que as diferenças (de pertença a uma língua, a uma cultura, a um status), não seja para aumentar o fosso do insucesso escolar?

Timbane (2014, p. 3) afirma que "A LP é a base para o sucesso dos alunos nas restantes disciplinas curriculares, pois é a base do ensino. Quem não domina esta língua fica condenado ao insucesso nas diversas disciplinas tais como história, geografia, ciências naturais, matemática, etc." Nesse aspecto devo concordar com esse autor, mas há uma série de aspectos que é importante colocar em análise. Segundo ele "Quem não domina esta língua fica condenado ao insucesso...", ora, é o que acontece com a maioria das crianças e jovens no sistema educativo. O discurso da sociedade é de que a escola não consegue pôr os alunos a ler e a escrever, que os alunos não desenvolvem hábitos de leitura, que o sistema educativo é fraco, os professores estão mal preparados, e assim por diante. Essa ideia também vem refletida no Plano Curricular do Ensino Secundário Geral (PCESG): "Em Moçambique, o ensino caracteriza-se por baixas taxas de conclusão do ensino primário e secundário. A pirâmide educacional caracteriza-se por apresentar uma base larga e um topo estreito [...]", (PCESG, p. 4), um pouco mais longe, p. 6 onde se faz referência a um estudo diagnóstico sobre o Ensino Secundário Geral (ESG), que revela que: "Da análise feita, pode-se concluir que os alunos revelam maiores dificuldades na expressão escrita particularmente na produção de textos bem estruturados, com sequência lógica e sem erros ortográficos facto que se reflete no desempenho dos mesmos nas restantes disciplinas". Podemos verificar ainda que um outro fator que gera dificuldades na escola, é a questão da variação linguística, abordada por Menezes:

As variações em língua portuguesa em Moçambique abrangem dimensões linguísticas, que incluem aspectos fonético-fonológicos, morfossintáticos, semântico-pragmáticos e retóricos. [...] Um fator evidente que dá um aspeto único ao português falado em Moçambique é a variação do sotaque que aparece em todas as línguas maternas de origem bantu e que, muitas vezes, surge em conexão com uma transferência de propriedades dessas línguas [...] Ex. a) Ensurdecimento das oclusivas sonoras, típicas dos falantes nativos do emakhuwa (PE: [bola] "bola"; PM: [bola]; Emakhuwa: [pola]; (PE: [buRu] "burro" PM) [buru]; Emakhuwa: puru]). (Menezes, 2013, p. 9).

Em certa medida, a ideia de uma língua que pela sua prática, vivência e contextos diferentes gera diversidades e torna a língua portuguesa mais rica e mais dinâmica é incontestável, e Monjane Henriksen espelha a mesma ideia quando afirma que: 
Apesar desta diversidade linguística elevada, é possível falar da unidade nacional no território moçambicano, veiculada principalmente através da língua portuguesa, que constitui um verdadeiro lugar de encontro de línguas e culturas. A questão actual não é se o português constitui ou não uma língua exógena ou endógena, se é ou não uma língua nacional-moçambicana, mas que se trata de uma língua também nossa, enriquecida e engrandecida pelo contacto entre os povos, culturas e línguas vernaculares moçambicanas. (Henriksen, 2017, p. 53).

Este ideal já o encontramos nos documentos orientadores e é o que que está refletido em textos de linguístas (Calvet, Zarate, Coste, e outros), quando se referem a necessidade de se ensinar/aprender tendo em conta a pluralidade de línguas e culturas. Ideia também exposta por Noa nos termos seguintes:

Existe uma dimensão incontornável quando se analisa os sujeitos e os produtos resultantes da colonização europeia em África: a questão identitária é, em grande parte dos casos, um fenómeno de alteridade. Isto é, é-se um ao mesmo tempo que se é outro. É-se igual ao mesmo tempo que se é diferente. Ou ainda, só se consegue efectivamente ser-se o mesmo, quando se consegue ser outro, mesmo que de forma nem sempre consciente.(Noa, 2017, pp. 121-122).

E acrescenta:

É, pois, no rastreio das representações inscritas em textos produzidos por autores de diferentes gerações da literatura moçambicana onde procuraremos reflectir na forma como as intersecções culturais a que fizemos referência geraram configurações em que identidade e alteridade se instituem como fundamentos de modos particulares de existir e de perceber o mundo. Sobretudo, a própria literatura, onde o exercício de ser um e outro se impõe como condição paradigmática, mas também problemática. (Noa, 2017, p. 121-122).

Todos esses autores concordam com a necessidade de olhar para a multiplicidade de línguas, culturas, modos de estar, de ser e de agir como um meio de promover as diferenças a favor de um desenvolvimento do indivíduo, onde quer que ele esteja. Noa aborda no seu texto a questão da literatura, fazendo um cruzamento entre autores moçambicanos ou ligados a Moçambique e às 
noções de identidade-alteridade e suas representações, as quais nos conduzem igualmente à língua e cultura.

Em relação ao contexto escolar, em particular, falando em tanto que formadora, numa instituição de formação de professores e me baseando na minha experiência de orientação de estágios pedagógicos, tenho verificado que existe um grande desencontro entre os vários actores do sistema educativo. Efectivamente, o real problema reside na coordenação das acções entre os conceptores de programas e currículos, entre as instituições de formação de professores e os professores em exercício nas escolas. Uma acção coordenada no sentido de traçar políticas linguísticas que favoreçam a expressão das várias línguas maternas bantus e as várias culturas presentes na escola, a fim de estabelecer o diálogo intercultural, por um lado, uma formação de professores que forme indivíduos para a pluralidade de expressão linguística, para a interculturalidade e a intercompreensão ${ }^{5}$, por outro lado e finalmente, uma escola que tenha no seu programa de acção, tanto no âmbito pedagógico como na extensão de actividades por meios das quais os alunos não se sintam estrangeiros, pelo fato de não se identificarem com a língua e com a cultura imposta pelo sistema. Isso não significa que se deve ensinar valendo-se de todas as línguas. Segundo Calvet (2007), citado por Antonucci Correa (2009, p. 75), "se todas as línguas são iguais aos olhos dos linguistas, essa igualdade se situa num nível de princípios, isto é, num nível extremamente abstrato. Mas, na verdade, todas as línguas não podem cumprir, igualmente, as mesmas funções", o que significa que o professor não precisa colocar as línguas bantu ao mesmo nível que as outras presentes na escola, ele deve sim estar preparado e sensibilizado para promovê-las por meio do mosaico que constitui a sala de aula, principalmente nas zonas urbanas, onde se depara com turmas heterogéneas do ponto de vista da origem geográfica e linguística. Falar de intercultura, conduz-me a abordar a questão das diferenças, pois numa situação como a de Moçambique, país multilingue e pluricultural, a promoção de línguas e culturas passa primeiro pelo reconhecimento de que as várias línguas em presença na escola, mesmo não tendo o mesmo estatuto, podem contribuir para um melhor processo de ensino-aprendizagem na medida em que muitos dos conteúdos abordados no meio formal, que é a escola, já são tratados empiricamente, pelos alunos, no seu meio familiar e muitas vezes estes têm algo a dizer considerando suas realidades. O diálogo intercultural permite que tudo seja aproveitado na escola. A experiência de uns, as histórias de outros, os vários raciocínios e os modos de pensar e de estar constituem um enriquecemento para o grupo classe e promove igualmente a intercompreensão. Um exemplo retirado dos livros escolares do ensino primário mostra que algumas figuras (em número considerável) ilustradas nos livros de português, por exemplo,

5 Intercompreensão em línguas. 
não têm em conta as diferenças de contextos. A representação de casa, de cama, de cozinha, de escola, não é a mesma, em função do contexto onde está inserido o aluno. Colocar uma imagem de casa, construída em material de alvenaria, como modelo de casa para todas as crianças moçambicanas, significa que: a criança que vive nas zonas rurais, a qual nunca de lá saiu e não conhece esse tipo de casa, ficará perdida e fora do contexto, se o professor não tiver a capacidade de usar a sua formação, os conhecimentos que detém e a experiência que possui para fazer a ponte entre a realidade do aluno e a do meio urbano, onde existem esse tipos de casa. Infelizmente, a maior parte dos professores, primários e secundários em exercício, não possuem uma formação para gerir essas situações na sala de aulas. A missão de formar, de colocar meios à disposicão das escolas e dos alunos é do Estado. Calvet, citado por Antonucci Correa, define:

[...] a linguística como o estudo das comunidades humanas através da língua. As línguas existem para servir aos homens e não os homens para servir à língua. Lembra que o planejamento linguístico, as escolhas a serem utilizadas para determinadas funções são atribuições do Estado, o qual, em seu campo de atuação, tem poder e meios de passar ao estágio do planejamento. (Correa, 2009, p. 74).

\section{Minhas questões do início}

Os três pontos por mim colocados no início deste texto, a saber: a) a definição da política linguística, b) as línguas e o sistema educativo e c) o ensino-aprendizagem num contexto multilingue e plurilingue serviram para orientar a minha análise por meio de aspectos que já constituem uma rotina nas diferentes discussões, tanto pelos responsáveis da educação, como pelas instituições de formação e a sociedade em geral.

Numa sociedade multilingue como Moçambique, as línguas e culturas estão expostas e se manifestam livremente nos indivíduos, de tal modo que não é possível separá-las uma das outras ou impedir que elas dialoguem e se adaptem aos contextos. No meio informal, tudo acontece de maneira natural. As línguas são usadas em função das necessidades dos indivíduos. Palavras e expressões são inventadas, adaptadas, emprestadas, etc. Enquanto que no meio formal, entram as regras, as normas e com isso entra a inibição, a proibição, o preconceito e a discriminação. 
A intercultura na escola apela ao diálogo de ideias, de saberes, de atitudes e de comportamentos. Para isso a escola deve estar preparada, o professor, a sociedade e os encarregados de educação necessitam de preparo para lidar com a diferença, não só em termos linguísticos e culturais, mas a outros níveis (equilíbrio do género, necessidades educativas especiais, diferença de religião e de cor da pele, etc.) e promover a alteridade. De que maneira? Fazendo valer as várias vozes presentes na escola, mobilizando conhecimentos e experiências trazidos de fora da escola, principalmente experiências decorrentes da educação informal e tradicional. Por exemplo, em português muitos falantes de língua materna bantu, no sul do país, não fazem a distinção entre as formas de tratamento, verificando-se ocurrências de "Tu" e "Você" dirigidas a mesma pessoa. As formas de tratamento em português exigem que se distinga tratamentos diferenciados em função da relação de proximidade ou de distanciamento entre as pessoas. Os termos "tu"/"Você"/“Senhor/Senhora", etc. não existem nas línguas bantus. Ora, um aluno que tenha uma língua materna bantu, desconhece ou ignora este aspecto na altura do seu processo de aprendizagem na escola. Para se chegar a essa constatação, é necessário que o professor procure saber, por exemplo, como funcionam as línguas maternas em relação às formas de tratamento, para que se possa corrigir o erro em português. Isso permitiria que houvesse uma interação envolvendo outras línguas e o seu modo de organização. As políticas linguísticas podem estar bem desenhadas e em acordo com o preceitoado nas didáticas e manuais de ensino. Mas enquanto cada sector funcionar de maneira isolada e não em cadeia, persistirão as dificuldades, multiplicar-se-ão as desculpas em relação ao insucesso escolar e o governo continuará a despender dinheiro em programas de recuperação, reformas e revisões. Cabe aos responsáveis da educação, que desenharam as políticas, assegurar que as condições estejam criadas no terreno, que as instituições de formação disponibilizem professores devidamente formados, a fim de que estejam diante dos vários desafios da educação. Para que o sistema funcione, é necessário que ele funcione em rede, onde cada um tem a sua missão, mas uns dependem dos outros para que a máquina funcione.

\section{REFERÊNCIAS}

Cadre Europeen Commun de Reference pour les Langues: apprendre, enseigner, evaluer -CECRL (2000). Disponível em: <https://www.coe.int/fr/web/common-european-framework-reference-languages $>$. Acesso em: 15 set. 2017.

Cavalli M.; Coste, D.; Crişan, A.; Van de Ven, P. L'éducation plurilingue et interculturelle comme projet. Division des Politiques Linguistiques, Strasbourg, 2009. Disponible em: $<$ www.coe.int/lang/fr $>$. Acesso em: 4 nov. 2017. 
Correa, D. A. Política linguística e ensino de língua. Calidoscópio, v. 7, n. 1, p. 72-78, jan/abr 2009.

Coste, D.; Moore, D.; Zarate, G. Compétence Plurilingue et Pluriculturelle. Vers un Cadre Européen Commun de référence pour l'enseignement et l'apprentissage des langues vivantes: études préparatoires, (Version révisée). Division des Politiques Linguistiques, Strasbourg, 2009, Conseil de l'Europe.

Henriksen, S. M. (2017). A unidade na diversidade nos espaços de língua portuguesa: o caso de Moçambique. In: Darbord, M.-A. Outras Margens: a vitalidade dos espaços de língua portuguesa. P.I.E. Peter Lang S.A., Éditions Scientifiques Internationales, Bruxelles, v. 15, p. 53-65, 2017.

Lemos, A. Contexte plurilingue au Mozambique: quelle identité, quelle culture? French Studies in Southern Africa, n. 41, p. 118-141, 2011. ISSN: 0259-0247.

Lemos, A. Enseignement bilingue au Mozambique: entre contraintes et avantajes. In: Maurer, Bruno. Les approches bi-plurilingues d'enseignement-apprentissage: autour du programme École et Langues Nationales en Afrique (ELAN-Afrique). Éditions des Archives Contemporaines (EAC): Paris, France, 2015.

Mabasso, E. Sobre a construção da variedade moçambicana da Língua Portuguesa (2014). Disponível em: <https://ventosdalusofonia.wordpress.com/2014/08/23/eliseu-mabasso-sobre-a-construcao-da-variedade-mocambicana-da-lingua-portuguesa/>. Acesso em: 20 set. 2017.

Menezes, L. J. J. M. Plurilinguismo, Multilinguismo e Bilinguismo: Reflexões sobre a Realidade Linguística Moçambicana. Revista Percursos linguísticos, 2013. Disponível em: <http://periodicos.ufes.br/percursos/article/view/4589>. Acesso em: 20 out. 2017.

Ministério da Educação e Cultura. Instituto Nacional do Desenvolvimento da Educação (INDE). Plano Curricular do Ensino Básico (PCEB): Objectivos, Políticas, Estrutura, Plano de Estudos e Estratégias de Implementação. Ministério da Educação: Maputo, Moçambique, 2003.

Ministério da Educação e Cultura. Instituto Nacional do Desenvolvimento da Educação (INDE). Plano Curricular do Ensino Secundário Geral (PCESG): Objectivos, Políticas, Estrutura, Plano de Estudos e Estratégias de Implementação. Ministério da Educação: Maputo, Moçambique, 2007.

Noa, F. Uns e Outros: imaginário, identidade e alteridade na literatura moçambicana. In: Darbord, M.-A. Outras Margens: a vitalidade dos espaços de língua portuguesa. P.I.E. Peter Lang S.A., Éditions Scientifiques Internationales, Bruxelles, v. 15, p. 122-132, 2017. Timbane, A. A. O ensino da língua portuguesa em Moçambique e a problemática da formação de professores primários, Artifícios, Revista do Difere, v. 4, n. 7, jun/2014.

Texto recebido em 29 de dezembro de 2017. Texto aprovado em 30 de dezembro de 2017. 